\title{
Osteopathic treatment of the genital descensus and its accompanying symptoms in women. A comparative pi- lot study of osteopathy and electrostimulation /bio- feedback for the pelvic floor.
}

Daniela Bogner ${ }^{1}$

\section{ABSTRACT}

Background: Genital descensus (POP = Pelvic Organ Prolapse) is a common condition among women (postpartum) in all age groups. The standard treatment is still surgical correction followed by conservative therapies. An alternative method of treatment by osteopathy is still not widespread.

Aims: There are treatment options analysed by osteopathy or PFMT (pelvic floor muscle training) with biofeedback/electrostimulation. The research question is: Is osteopathy in addition to the active practice by means of electrostimulation and biofeedback more successful than the practice using only the electrostimulations/biofeedback device?

Methods: Clinical comparative study of 30 women. Throughout the observation period, all participants should get a biofeedback device. Half the women will also receive an osteopathic treatment. The primary target parameter of the score from the bladder SPSQ questionnaire will be evaluated. As secondary parameters, a further 4 scores from the questionnaire, a gynaecological diagnosis and the electromyogram of the biofeedback device are determined.

Results: Both methods show a significant improvement (experimental group: $p<0.001$; control group: $p=0.024$ ) in the symptoms of genital prolapse of the bladder score. The difference in improving the symptoms in the experimental group is significantly higher $(p=0.005)$ compared to the control group. Within the secondary parameters is the improvement of gynaecological diagnosis and an enormous increase in muscle strength is visible.

Conclusions: Both methods represent a relevant alternative to surgical intervention. Osteopathic treatment is a very valuable add-on to standard conservative treatment.

Keywords: genital descensus, pelvic organ prolapse, pelvic floor muscle training, biofeedback, osteopathy

DOI: https://doi.org/10.35740/EJOR.2019.1.1.4 


\section{Background}

Pelvic organ prolapse (POP) or Genital Descensus is a common female condition characterised by pelvic floor disorders in women mostly over the age of 60 years [1]. Typical symptoms are vaginal bulging and pelvic heaviness [2] but also stress urinary incontinence, bowel symptoms and sexual dysfunction [3].

Definition of the POP: meaning a general descent of the genital area (bladder, uterus, vagina). This can have different variants like Urethrocele, Cystocele, Rectocele, and so on. It depends on which organ descends into the vagina, mostly it is a combination [4, 5]. Since 1996 the International Continence Society (ICS) has taken the standardising terminology (Figure 1) for POP called POPQ system by Bump et al. (1996) [6].

Especially at the beginning, the POP is in most cases without symptoms or the symptoms of the bladder are dominant. Frequently, urinary incontinence gets better in the advanced stage of POP because the urethra is getting kinked. The root cause of POP is weak pelvic floor muscles (PFM). The condition can significantly impact the daily activities, and quality of life of the women affected $[7,4,8]$.

There are many causes for a POP, but the most significant factors for developing a prolapse are advancing age and parity [9]. The causes of descent are complex and usually a combination of risk factors and external influences. The typical symptoms of POP appear rather delayed. This generates a very late diagnosis of POP which incorporates a high grade (II-IV) according to the POP-Q System. Due to the high-grade diagnosis, women are often convinced to undergo surgery [10].

\begin{tabular}{|c|c|}
\hline Stage (I) & Most distal portion of the prolapse is more than $1 \mathrm{~cm}$ above the level of the hymen. \\
\hline Stage (II) & Most distal portion of the prolapse is $1 \mathrm{~cm}$ less proximal to or distal to the plane of the hymen. \\
\hline Stage (III) & The most distal portion of the prolapse is more than $1 \mathrm{~cm}$ below the plan of the hymen. \\
\hline Stage (IV) & Complete eversion of the total length of the lower genital tract is demonstrated. \\
\hline
\end{tabular}

Figure 1. Prolapse staging - 0 - IV (Haylen et al. (2010))
Current treatment options for POP are surgery and conservative methods. A common conservative treatment is physiotherapy, pessaries and hormone therapy. Pelvic floor muscle training (PFMT) in particular, is applied by qualified physiotherapists. Very often, the physiotherapy is enhanced by using electrostimulation and biofeedback devices which train the PFM [11]. In the past, two studies $[12,13]$ were done in osteopathy compared with physiotherapy (in both cases with-in a clinical trial study).

In this work, the effects of conservative methods are analysed. More specifically, the possibilities of treatment with osteopathy and PFMT are the focus of a clinical trial study.

The research question is: There is no difference in the improvement of the descent of the genital and its accompaniments in the observation period of 5 months between the experimental group and the control group.

\section{MATERIAL AND METHODS}

In this work, the impact of osteopathy on the symptoms of POP is evaluated with a clinical trial study. The study was applied to 30 women. The selection of the women was limited to the following conditions (the most important ones): Inclusion criteria: women of full age, diagnosed descensus (I-III) by a gynaecologist, more than one of the symptoms (-bulge in the vagina, pain in the lower back or the underbelly, symptoms of bladder or bowel) 
Exclusion criteria: acute inflammation in the abdominal area, infections, tumours, sexually transmitted disease, pregnancy, neurological illness, POP (IV)

All 30 women were advised to execute the pelvic floor muscle training (PFMT) within the whole observation period of 6 months. The training was executed with the Electrostimulation - and Biofeedback-device of the TIC-Med-Company. The device is called SYNTIC.

The group was divided into two parts whereby the trial group was additionally treated with osteopathy, and the control group was only supported in the application of the PFMT.

Table 1 illustrates the relevant time points during the study run time. At time point $t 0$ the selection and the mapping of the patients took place, as well as the first medical examination by the gynaecologist. The most important time point is $t 1$, where the PFMT is explained and started, the first test for the muscle contraction is derived online from the SYNTIC-device. Furthermore, the trial group is treated with osteopathy-thy within the first week after $\mathrm{t} 1$. The end time point of the treatment is defined with $t 2$. Between $t 1$ and $t 2$, the patients of the trial group are treated with a minimum of 4 up to 6 osteopathic sessions. This amount of sessions was chosen based on experience from previous work [12-13].

At $\mathrm{t} 2$ the PFMT is finished and a second online test of the muscle contraction is derived from the SYNTIC-device. Also, a final examination by the gynaecologist is mandatory. The training phases of the patients were stored in the SYNTIC-device and were read out after the training period.

The following measurements were used for dataevaluation:

- SPSQ - (Sheffield-Prolapse-SymptomQuestionnaire)

- Gynaecologist examination report of Descensus score - based on Scotty et al [14].

- Online measurement of muscle contraction with SYNTIC-device

All three measures are applied at time point $\mathrm{t} 1$ and $\mathrm{t} 2$.

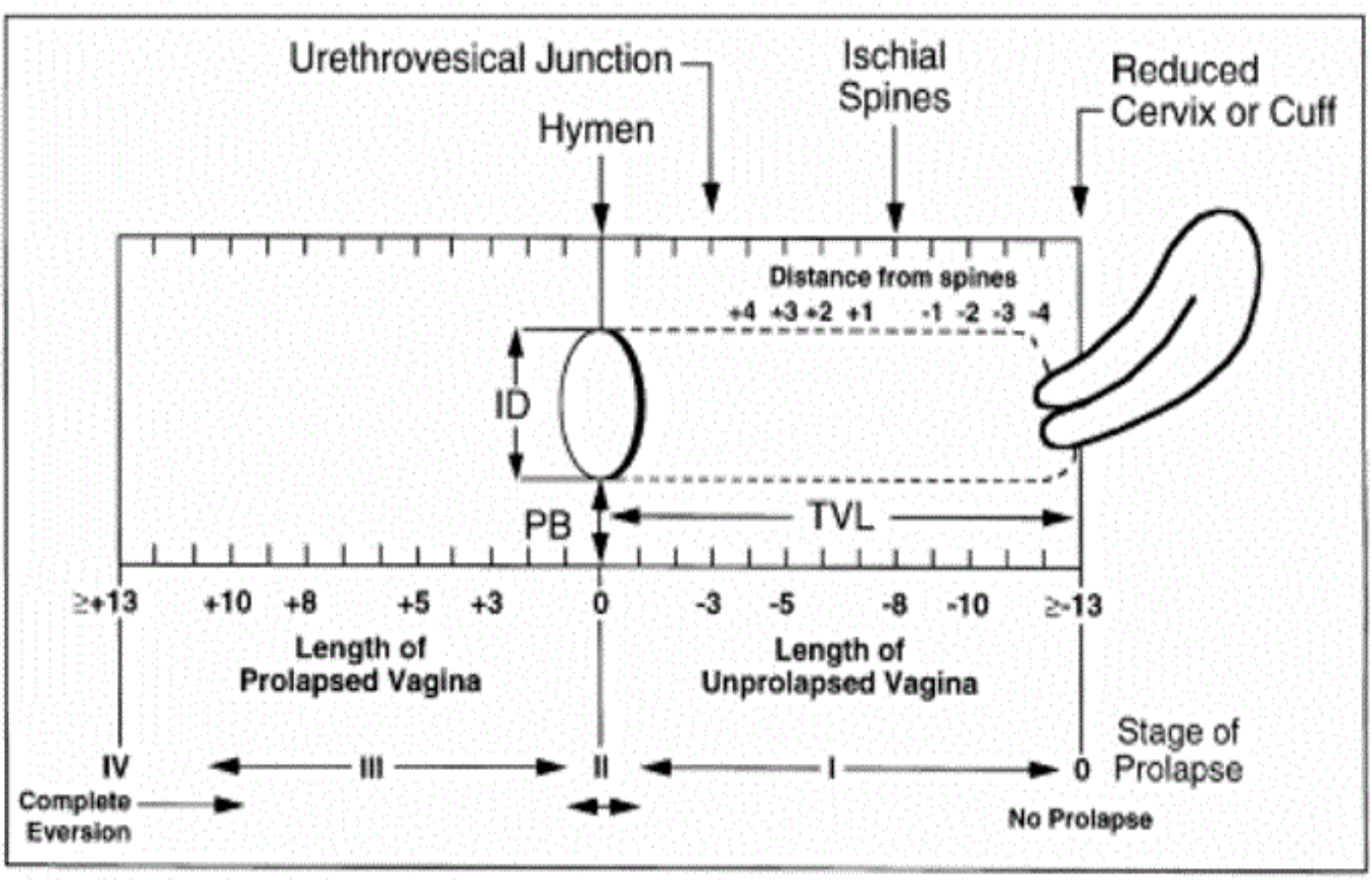

Figure 2. B clinical findings sheet - Scotti et al. (2000) 
The primary tool for data acquisition within the study is the SPSQ (Sheffield-Prolapse-SymptomQuestionnaire). The SPSQ is divided into five domains, which are bladder, prolapse, bowel, sexual and vaginal, and lifestyle symptoms. This questionnaire had to be answered by the patients at time point $\mathrm{t} 1$, and a second independent answer was filed at time point $\mathrm{t} 2$.

The second tool for data acquisition is the report of the gynaecologist, which delivers the score of descensus. The report is based on Scotty et al. [14]. Figure 2 shows the normalisation of the position of the uterus. The maximum amount of the prolapse is limited to $+/-13$, whereby the hymen is defined as 0 . The gynaecologist reports the visible location for each patient.
A further parameter is derived from the SYNTIC device. The device allows an online measurement of the existing muscle contraction. This is measured with a sequence of contraction and relaxation of the patient during a session in the practice of the osteopath.

\section{Statistical methods}

The three above named measurements were analysed with statistical methods. Due to the nonGauß-distribution of the data, the Mann-Whitney-U-test was chosen for analysing the correlated measurement results. This test allows the calculation of the significance ( $p$-value) between two groups (e.g. control group and trial group).

Table 1. Relevant time points

\begin{tabular}{|c|c|c|c|c|}
\hline $\begin{array}{c}\text { Time } \\
\text { Frame in }\end{array}$ & $\begin{array}{l}\text { Time } \\
\text { Point }\end{array}$ & \multicolumn{2}{|c|}{ Procedere } & Comment \\
\hline & & $\begin{array}{l}\text { Osteopathy group } \\
\text { (Intervention group) }\end{array}$ & $\begin{array}{l}\text { Electro-/biofeedback group } \\
\text { (Control group) }\end{array}$ & \\
\hline & $10 a$ & \multicolumn{2}{|c|}{ Randomisation } & \\
\hline & $10 \mathrm{~b}$ & Patients gynecologist & Patients recommendation & Recruiting \\
\hline & $10 d$ & \multicolumn{2}{|c|}{$\begin{array}{l}\text { First contact (therapist) / clarification of facts / handing the } \\
\text { questionnaire }\end{array}$} & $\begin{array}{l}\text { Personal by } \\
\text { phone }\end{array}$ \\
\hline \multirow[t]{2}{*}{0} & 11 & \multicolumn{2}{|c|}{$\begin{array}{l}\text { EMG-online measurement with SYNTIC } \\
\text { Completing questionnaire } \\
\text { Osteopathic findings }\end{array}$} & \\
\hline & & \multicolumn{2}{|c|}{$\begin{array}{l}\text { PFMT - right contraction } \\
\text { Explanation of the SYNTIC-device }\end{array}$} & \\
\hline 1 & $11 a$ & First treatment & & \\
\hline $1-16$ & $11 b$ & $\begin{array}{c}4-6 \text { osteopathic sessions / á } \\
45 \text { min in time from } 2-4 \\
\text { weeks }\end{array}$ & $\begin{array}{l}1 \times \text { per month phone call } \\
\text { with the participants } \\
\text { (motivation) }\end{array}$ & $\begin{array}{l}\text { Pragmatic clinical } \\
\text { trial }\end{array}$ \\
\hline $17-18$ & 12 & \multicolumn{2}{|c|}{$\begin{array}{l}\text { EMG-online measurements }+ \text { questionnaire + osteopathic } \\
\text { findings }\end{array}$} & \\
\hline $18-19$ & $12 a$ & \multicolumn{2}{|c|}{ Examination of the gynecologist (grades of POP) } & \\
\hline $20+$ & $12 b$ & & $4-6$ osteopathic sessions & $\begin{array}{l}\text { Both groups get } \\
\text { the equal } \\
\text { treatment }\end{array}$ \\
\hline
\end{tabular}




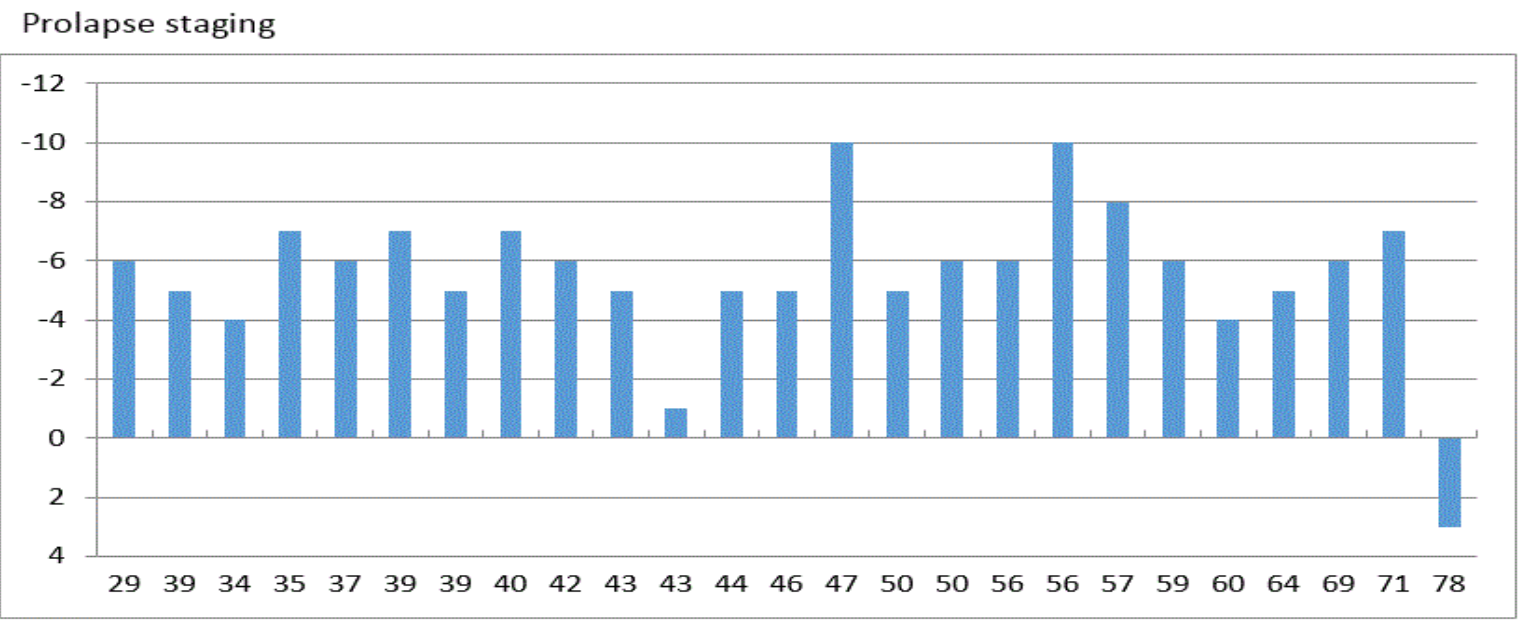

age

Figure 3. Prolapse staging - classified in age at time point t1

For the analysis of intervention, the difference between the two scores are calculated (e.g. score @ t1 - score@ @ 2). Furthermore, the average value and standard deviation (sigma value) are calculated out of the differences. To prove the hypothesis, the p-value between the two groups is calculated with the independent t-test and the Mann-Whitney-U-Test.

All data is collected within the program Excel from Microsoft. The t-test is available as a macro, and the Mann-Whitney-U-test has been implemented by formulas according to [15]. The data is also illustrated in boxplots.

\section{RESULTS}

In the first phase of the work, 33 women were recruited. Three women did not fulfil the criteria to start the study and five women dropped out during the run time of the study. Finally, 12 members were evaluated out of the trial group and 13 members within the control group. Figure 3 shows the descensus reported from the gynaecologist at t1 and sorted along the age of both groups. The recruited patients show a very large distribution in age. What is remarkable is the presence of massive descensus and accomplished symptoms in young women. This proves that descensus is not only present within older women. The scale of descensus is normalised to $+/-13$ within the report based on Scotty et al. [14] (figure 2).

Within the whole group, there is only one patient with a positive scale, which means the uterus is outside of the hymen. The majority of patients are in the group 40 to 61 years of age, and this corresponds to the literature [1]. This group is, therefore, the main target for conservative methods to improve the descensus and accomplished symptoms.

Both groups were compared at t1 in age, size, amount of pregnancies, weight and duration of symptoms. The intragroup parameters did not show a significant difference based on calculated $\mathrm{p}$-value. The descensus score received from the gynecologist and the measured muscle contraction is also compared between both groups - also here no significant difference has been detected. The most important parameters for comparison are the scores evaluated by the questionnaire (table 2).

The scores for prolapse and bladder show no significant difference between the two groups. The main difference can be detected in the score for bowel. This score is not used for the evaluation of the research hypothesis. In the scores vaginal/sexual and lifestyle a very good match between the groups is given. 
Table 2. Group rates - at timepoint t1 - SPSQ (domains)

\begin{tabular}{|c|c|c|c|c|c|}
\hline & $\begin{array}{l}\text { Osteopathy + } \\
\text { SYNTIC-device } \\
\text { (Intervention } \\
\text { group) } \\
\text { mean } \pm \text { SD }\end{array}$ & $95 \% \mathrm{Cl}$ & $\begin{array}{c}\text { SYNTIC-device } \\
\text { (Control-group) } \\
n=13 \\
\text { mean } \pm \text { SD }\end{array}$ & $95 \% \mathrm{Cl}$ & $\begin{array}{c}\text { p-value } \\
\text { (Mann-Whitney-U- } \\
\text { test) }\end{array}$ \\
\hline Prolapse & $9.7 \pm 2.1$ & 1.3 & $11.2 \pm 4.7$ & 2.5 & 0.586 \\
\hline Bladder & $11.7 \pm 1.9$ & 1.1 & $10.7 \pm 1.8$ & 1.0 & 0.301 \\
\hline Bowel & $8.8 \pm 1.7$ & 1.0 & $6.6 \pm 1.8$ & 1.0 & 0.011 \\
\hline $\begin{array}{l}\text { Vaginal-/ sexual } \\
\text { symptoms }\end{array}$ & $13.8 \pm 2.1$ & 1.2 & $14.5 \pm 3.4$ & 1.9 & 0.663 \\
\hline Lifestyle & $11.5 \pm 1.9$ & 1.9 & $10.5 \pm 3.7$ & 2.0 & 0.550 \\
\hline
\end{tabular}

For proving the research hypothesis, the score for the bladder is analysed in detail. The score for the bladder is the primary target parameter. To obtain this, the difference between $\mathrm{t} 1$ and $\mathrm{t} 2$ within one group is calculated. Figure 4 shows the boxplot of the computed results within the control and the intervention group.

Figure 4 clearly illustrates the improvement of the symptoms related to bladder within the intervention group - the median is at 3.5 score points. Within the control group, the median shows an improvement of only 1 score point. This correlates well to the p-value calculation illustrated in table 3 .

In table 3 all calculated score differences of the questionnaire are shown. The average value and the standard deviation of the control and intervention group are listed. In the next row, the difference of the average value is listed. The p-value is calculated with the independent T-test and the Mann-Whitney U-Test.

Both groups show an improvement in the score for the bladder. However, in the comparison, a significantly better improvement within the intervention group correlated to the control group has

Table 3. Differences - both groups; overview of all scores

\begin{tabular}{|c|c|c|c|c|c|}
\hline & $\begin{array}{c}\text { Osteopathy + SYNTIC- } \\
\text { device } \\
\mathbf{n}=12 \\
\text { (Intervention group) } \\
\text { mean } \pm \text { SD }\end{array}$ & $\begin{array}{c}\text { SYNTIC-device } \\
\text { (Control-group) } \\
n=13 \\
\text { mean } \pm \text { SD }\end{array}$ & $\begin{array}{l}\text { Difference of } \\
\text { the mean }\end{array}$ & $\begin{array}{c}\text { p-value } \\
\text { (Independent } \\
\text { T-test) }\end{array}$ & $\begin{array}{c}\text { p-value } \\
\text { (Mann- } \\
\text { Whitney-U- } \\
\text { test) }\end{array}$ \\
\hline Prolapse & $-3.75 \pm 1.66$ & $-1.85 \pm 0.80$ & -1.90 & 0.003 & 0.005 \\
\hline Bladder & $-2.5 \pm 1.38$ & $-2.35 \pm 3.51$ & 0.35 & 0.677 & 0.550 \\
\hline Bowel & $-1.92 \pm 1.62$ & $-0.62 \pm 1.39$ & -1.30 & 0.043 & 0.026 \\
\hline $\begin{array}{l}\text { Vaginal-/ sexual } \\
\text { symptoms }\end{array}$ & $-3.42 \pm 2.31$ & $-2.77 \pm 2.17$ & -0.65 & 0.633 & 0.497 \\
\hline Lifestyle & $-3.75 \pm 2.49$ & $-1.77 \pm 3.06$ & -1.98 & 0.097 & 0.103 \\
\hline
\end{tabular}


been achieved. The score for prolapse also shows an improvement in both groups. However, the intervention group has a similar change compared to the control group, which results in a non-significant change. There are two secondary parameters to support the result of the questionnaire. The descensus score from the gynaecologist examination also shows a very interesting result. Figure 5 shows the difference illustrated in a box plot between $\mathrm{t} 1$ and $\mathrm{t} 2$ for both groups.

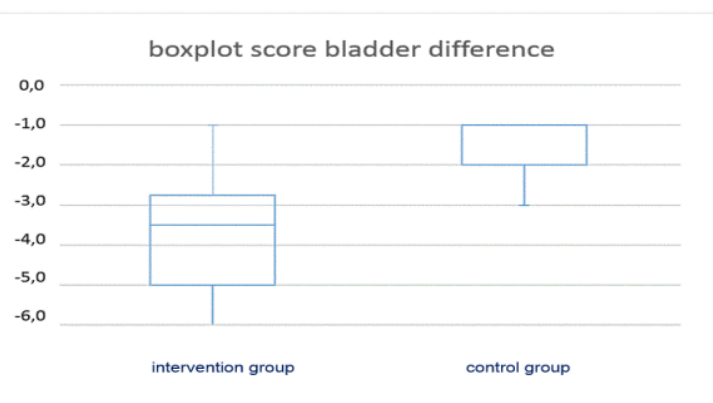

Figure 4. Boxplot score

It is visible that the intervention group shows a remarkable improvement in the descensus score compared to the control group. The difference between the two groups is also calculated with the Mann-Whitney U-Test, which results in a p-value smaller than 0.001 , proving a significant improvement within the intervention group. In contrast

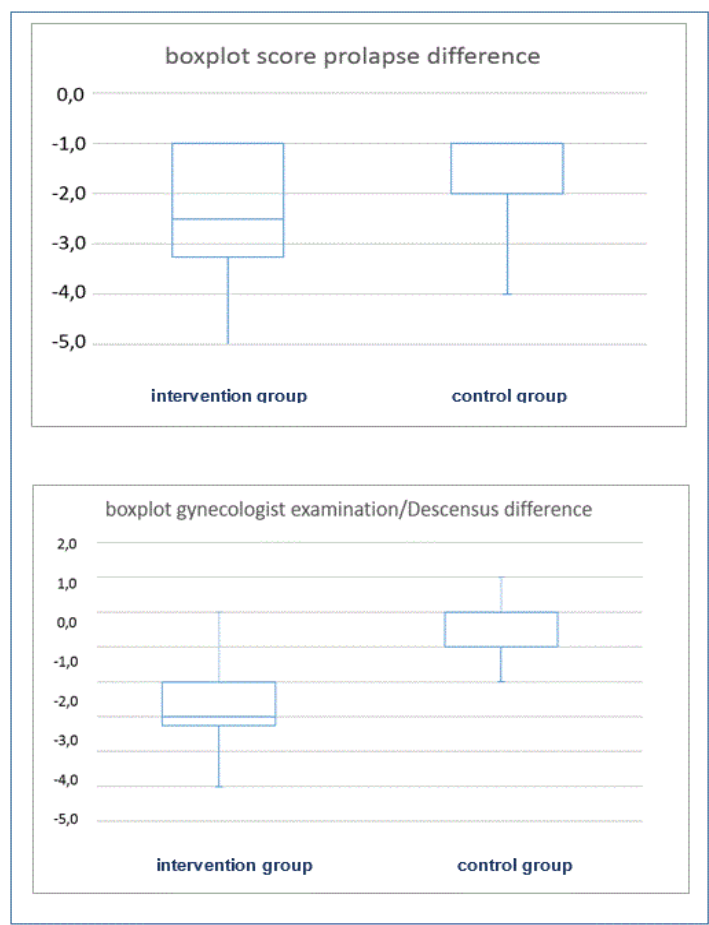

Figure 5. Boxplot score prolapse (SPSQ); gynecologist examination

to this result, the prolapse score of the questionnaire doesn't show a significant improvement. In figure 5 the difference in the prolapse score is also illustrated and shows almost the same tendency in both groups, meanwhile the p-value calculation shown in figure 5 reports a non-significant change within this score. This proves that the

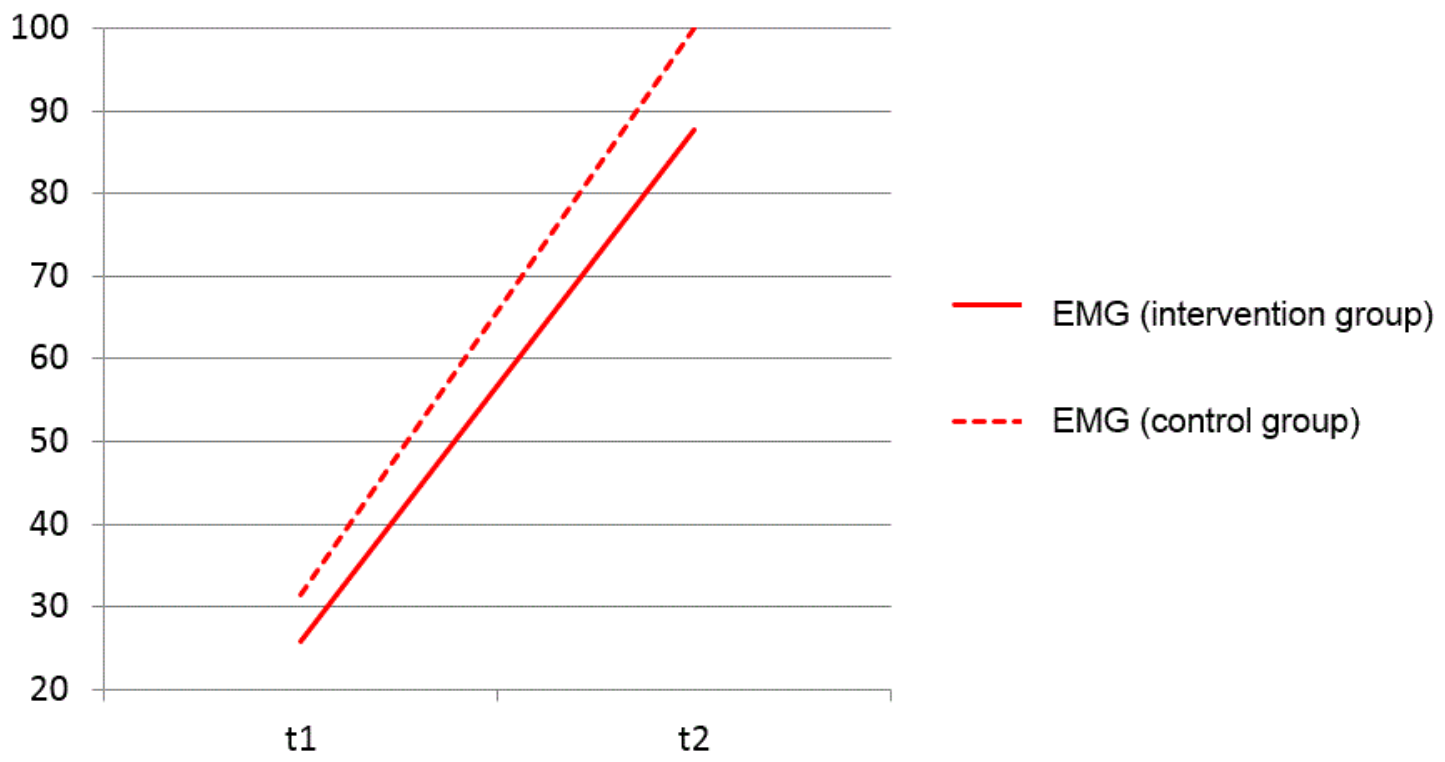

Figure 6. EMG-amplitude; improvement both groups 
perceived status deviates clearly from the visible status re-ported by the gynaecologist.

Another secondary target parameter is the measurement of muscle contraction. Here the absolute value is illustrated in the diagram shown in figure 4. All women started with a small amplitude visible in the online measurement. After the training period, both groups improved by factors in the amplitude. This finding is much clearer in the plot of the absolute numbers (the differences don't show a big deviation). One patient improved her muscle contraction by approximately 300\%. She used the device almost daily to perform a training session. The results prove the positive impact of training sessions and the muscle condition. The $\mathrm{p}$-value calculation of the differences within both groups does not report a significant change in the intervention group $(\mathrm{p}$-value $=0.913)$. This $\mathrm{pa}$ rameter does not support the result of the bladder score. However, the $\mathrm{p}$-value of both groups between $\mathrm{t} 1$ and $\mathrm{t} 2$ result in significant improvement (p-value@intervention<0.001,p-value@control $=0.005)$.

\section{DISCUSSION}

In this study, the intervention group was regularly under the treatment of the osteopath. These appointments were also an important support and motivation to the women to carry out the muscle training. A clear difference between the groups was visible in the executed training sequences, due to the missing motivation of the members within the control group.

The result of the improvement (score differences) of the bladder score within the intervention and control group shows a significant difference. The result is far beyond the defined significance level and validates the alternative hypothesis. This means that osteopathy has a direct impact on the improvement of the genital descensus. This result is manifested by the secondary parameters, especially the diagnosed descensus score. This score also shows a significant improvement in the intervention group.

The regular training with the SYNTIC device generated in both groups a massive improvement of the muscle contraction. In some cases, the improvement was up to $300 \%$. This substantial change makes the contribution of an osteopathic therapy invisible. The $\mathrm{p}$-value of the differences in the EMG Amplitude within both groups doesn't show a significant improvement in the intervention group. Based on this result, the research hypothesis is valid. A reduction of the result within the primary parameter bladder score is not allowed.

An essential remark concerning the results is the uncertainty of the data source. The scores within the questionnaire are based on the constitution of the patient. The results are strongly correlated to e.g. menstruation cycle, physical condition and time of day. This uncertainty is partly compensated by the secondary parameter descensus score which is reported independently by the gynaecologist.

The application of the SYNTIC device showed in both groups a definitive improvement of the symptoms, but an accompanying osteopathic treatment can clearly increase the success.

This result is almost identical to the results of Amendt and Thannheimer [12]. They reported a significant improvement in both groups (physiotherapy and osteopathy). The effect in the intervention group was $\mathrm{d}=2.09$ and in the control group $\mathrm{d}=0.67$. It is remarkable that this work achieved almost the same effects $(d=2.04$ and $\mathrm{d}=0.91)$. The similar results are also visible in the differences between the intervention and control group in both studies. The contribution of osteopathy in combination with active therapy is proved within this study.

\section{CONCLUSIONS}

This work describes the result of a clinical study of 30 women with genital descensus. Half of the women have been treated with osteopathy and biofeedback muscle training, the other half with muscle training only. The target of the work was to analyse the effect of osteopathy on the improvement of descensus genitals and the symptoms. To achieve a comparison, the Sheffield Prolapse Symptom Questionnaire“ (SPSQ) has been used. The bladder score was chosen as the 
primary parameter. As two secondary parameters the findings sheet by Scotti et al. (2000) (figure 2) and the online measurement of the biofeedback device was chosen.

The application of the biofeedback device resulted in a significant improvement in both groups. In both groups, pelvic floor muscle training was applied, which proved a positive influence on the symptoms of the bladder score. The influence of osteopathy is proven by calculating the differences within the two groups and performing a statistical p-value calculation. The differences also show a significant improvement in the intervention group. This concludes that osteopathy makes a major contribution to the improvement of the symptoms derived from genital descensus. The result is manifested by the second parameter of the findings sheet (gynaecologist). Also, the differences of this parameter results in a significant improvement.

A very important result is the improvement in muscle contraction. Both groups improved by $300 \%$ on average.

This work highlights the huge potential of conservative methods in the treatment of genital descensus and related symptoms.

\section{Discloser}

The author has no personal financial or institutional interest in any of the materials or devices described in this article.

\section{Author details}

1 Praxis Bogner, Austria

\section{Correspondence}

Sonnenhangweg 10, 9241 Wernberg, Austria office@praxisbogner.at

Received: 01 October 2019 Accepted: 28 November 2019 Published: 29 December 2019

\section{REFERENCES}

1. Alcalay, M., Stav, K., \& Eisenberg, V. H. (2015). Family history associated with pelvic organ prolapse in young women. International Urogynecology Journal, 26(12), 1773-1776.

https://doi.org/10.1007/s00192-0152779-5

2. Haylen, B., De Ridder, D., Freeman, R., Swift, S., Berghmans, B., Lee, J., ... Schaer, G. (2010). An International Urogynecological Association (IUGA)/International Continence Society (ICS) Joint Report on the Terminology for Female Pelvic Floor Dysfunction. Textbook of Female Urology and Urogynecology, Third Edition, 1090-1105. https://doi.org/10.3109/9781439807217$\underline{111}$

3. Maher, C., Feiner, B., Baessler, K., \& Schmid, C. (2013). Surgical management of pelvic organ prolapse in women. Cochrane Database of Systematic Reviews.

https://doi.org/10.1002/14651858.cd004 014.pub5

4. Jelovsek, J. E., Maher, C., \& Barber, M. D. (2007). Pelvic organ prolapse. The Lancet, 369(9566), 1027-1038.

https://doi.org/10.1016/s01406736(07)60462-0

5. M. B. J. D. Kuncharapu, "Pelvic organ prolapse," American Family Physician, vol. 81, no. 9, pp. 1111-1117, 1 May 2010.

6. Haylen, B. T., Maher, C. F., Barber, M. D., Camargo, S., Dandolu, V., Digesu, A., ... Withagen, M. I. J. (2016). An International Urogynecological Association (IUGA) / International Continence Society (ICS) Joint Report on the Terminology for Female Pelvic Organ Prolapse (POP). Neurourology and Urodynamics, 35(2), 137-168. https://doi.org/10.1002/nau.22922

7. DeLancey, J. O. L. (2002). Fascial and muscular abnormalities in women with urethral hypermobility and anterior vaginal wall prolapse. American Journal of Obstetrics and Gynecology, 187(1), 93-98. 
https://doi.org/10.1067/mob.2002.12573

$\underline{3}$

8. Weber, A. M., \& Richter, H. E. (2005). Pelvic Organ Prolapse. Obstetrics \& Gynecology, 106(3), 615-634.

https://doi.org/10.1097/01.aog.00001758 32.13266.bb

9. Hagen, S., Stark, D., Glazener, C., Dickson, S., Barry, S., Elders, A., ... Wilson, D.

(2014). Individualised pelvic floor muscle training in women with pelvic organ prolapse (POPPY): a multicentre randomised controlled trial. The Lancet, 383(9919), 796-806. https://doi.org/10.1016/s01406736(13)61977-7

10. Schaffer, J. I., Wai, C. Y., \& Boreham, M. K. (2005). Etiology of Pelvic Organ Prolapse. Clinical Obstetrics and Gynecology, 48(3), 639-647. https://doi.org/10.1097/01.grf.00001704 28.45819.4e

11. B. Carrière, "Beckenboden, Physiotherapie und Training," in Beckenboden, Physiotherapie und Training, Stuttgard, Thieme, 2012, p. $222 \mathrm{ff}$.

12. J. Amenth and Y. Thannheimer, Die osteopathische Behandlung von Frauen mit Gebärmuttersenkung, Schule für klassische osteopathische Medizin, 2011.

13. B. Kocheise-Miller and K. Quell, Die osteopathische Behandlung von Frauen mit Descensus uteri, College Sutherland: DOArbeit, College Sutherland, 2008.

14. Scotti, R. J., Flora, R., Greston, W. M., Budnick, L., \& Hutchinson-Colas, J. (2000). Characterizing and Reporting Pelvic Floor Defects: the Revised New York Classification System. International Urogynecology Journal, 11(1), 48-60. https://doi.org/10.1007/s001920050010

15. C. Zaiontz, 21 März 2016. [Online]. Available: http://www.real-statistics.com/nonparametric-tests/mann-whitney-test/.

\section{RIGHTS AND PERMISSIONS}

This article is distributed under the terms of the Creative Commons Attribution 4.0 International License, which permits unrestricted use, distribution, and reproduction in any medium, provided you give appropriate credit to the original author(s) and the source, provide a link to the Creative Commons license https://creativecommons.org/licenses/by/4.0/, and indicate if changes were made. 